\title{
Memoria crítica, working memory y pensar novelesco en La noche de los tiempos de Antonio Muñoz Molina
}

La noche de los tiempos (2009), de Antonio Muñoz Molina, constituye una novela histórica que debe ser comprendida en función del debate español sobre la "memoria histórica". El presente estudio empieza rastreando los artículos comprometidos del autor que preceden y preparan la novela (un epitexto con efecto paratextual), y pone de relieve cómo forjan un mito republicano que se reivindica no solo en tanto recuperación de una herencia sino como referencia para enjuiciar el presente y fundamentar un nuevo porvenir. Luego, examina en qué medida y de qué manera la novela, en especial gracias a las especificidades del pensamiento ficticio, constituye una aportación original: por una parte, con respecto a dichos artículos, cuyo ideario acaba socavando al mismo tiempo que lo exalta, y, por otra, de cara a la memoria controvertida de la Guerra Civil, superando los paradigmas habituales del reconocimiento y de la instrumentalización hacia la construcción de un discurso complejo y no partidista, caracterizado por una representación densísima y polifónica, la ejemplaridad filosófica y un metadiscurso tan crítico como autocrítico.

La noche de los tiempos se publicó en noviembre de 2009. En los medios informativos, se solía presentar como la esperada suma novelesca de Antonio Muñoz Molina (AMM) sobre la Guerra Civil, y su toma de posición con respecto al "debate" muy candente sobre la (mal) llamada "memoria histórica". ${ }^{1}$ La Ley de Memoria Histórica, ${ }^{2}$ propugnada por el gobierno socialista de José Luis Rodríguez Zapatero, había sido aprobada en 2007, en un contexto político e ideológico altamente polarizado (del que, por cierto, procuraban desvincularse las diversas asociaciones para la recuperación de la memoria histórica). ${ }^{3}$ Se correspondía con la voluntad de legitimar y promover otra memoria colectiva (la de los vencidos de la Guerra Civil), compensando las injusticias del Pasado, e incluso de desplazar definitivamente la memoria colectiva franquista. ${ }^{4}$ Durante la larga dictadura, esta se había impuesto como la oficial y la pública (lo cual no impidió que evolucionara con el discurso que la constituía), luego había conservado su hegemonía durante la Transición (por inercia, en nombre de un pragmático pero quizás mítico "pacto de silencio"), y, a pesar de treinta años de democracia y de una ingente labor historiográfica, 
sobrevivía con sus mitos y su maniqueísmo en amplios sectores de la derecha y de la sociedad civil. De hecho, en los primeros años del nuevo siglo se había observado una ola de obras supuestamente "revisionistas" que, con gran éxito editorial, reciclaban el discurso de la memoria franquista, no vacilando en increpar la historiografía universitaria - la cual reaccionaba subrayando el carácter fundamentalmente ideológico y anticientífico de dichas obras (Cenarro; Moradiellos). Este es el contexto en que se concibió, escribió y publicó La noche de los tiempos, y no cabe duda, efectivamente, de que la novela deba comprenderse en función de él, si bien, como veremos, habrá que ampliar dicha perspectiva. Por otra parte, la nueva obra se inscribía dentro de una trayectoria literaria personal en que la Guerra Civil se había tematizado desde finales de los años ochenta (recordemos Beatus Ille, 1986; Beltenebros, 1989; y El jinete polaco, 1991). La pregunta que quisiera plantear en esta contribución es la siguiente: ¿en qué medida y de qué manera La noche de los tiempos constituye una aportación original a la memoria de la Guerra Civil y al debate sobre la memoria histórica? Es una cuestión compleja, que además implica otras, como la articulación del Pasado y del Presente, de la ficción y de la Historia, $\mathrm{y}$, sobre todo, la de la especificidad del discurso novelesco. Para contestarla, empezaré con un rodeo por algunos artículos que escribió Muñoz Molina como intelectual comprometido: constituyen los pre-textos (epitextos indirectos con efecto paratextual) y el subtexto ideológico (lato sensu) de la novela.

HACIA UNA MEMORIA CRÍTICA Y ACTIVA

Antes que nada, conviene recordar que, en La noche de los tiempos, el protagonista principal, Ignacio Abel, cuya trayectoria existencial y punto de vista (toda su vida afectiva y mental) acompañamos a través de la mirada y la imaginación de un narrador extradiegético que lo alcanza todo y escribe en tercera persona, encarna de manera emblemática una posición política e intelectual (entre otras muchas cosas, porque es todo un personaje, con sus luces y sus sombras). ${ }^{5}$ Esto es, en el Madrid de 1936, simboliza la postura del republicano ilustrado y progresista, afín a los ideales de la Institución Libre de Enseñanza y de la Residencia de Estudiantes, consciente de las injusticias sociales y socialista, pero moderado y reformista, que presencia con escepticismo despectivo y luego horror la irresponsable exacerbación de las pasiones políticas, los fanatismos ideológicos y sus mentirosas propagandas, los crímenes y la impunidad de las diversas facciones. Es decir, representa el "patriota de corazón de la República española", que "no se casaba con nadie", tan crítico con los extremismos de izquierdas como con los de derechas. ${ }^{6}$ Esta 
posición, que pretende una ecuanimidad au-dessus de la mêlée y se correspondería con la postura racional y razonable del autor implícito, ${ }^{7}$ era y sigue siendo atípica y mal comprendida en un contexto ideológico fácilmente maniqueo o por lo menos dualista; asimismo atípica en la última generación de novelas de la Guerra Civil en que, generalmente desde un imaginario de izquierdas y la reivindicación de la memoria de los vencidos, se suele buscar la empatía emocional y acrítica. ${ }^{8}$

En realidad, dicha postura del autor implícito se detallaba y argumentaba en la producción periodística de AMM, en especial en un artículo clave que se publicó en la "Tribuna" de El País el 24 de abril de 2006: "Notas escépticas de un republicano", cuyo título prefigura el estado de espíritu del futuro protagonista ficticio $(\mathrm{y}$, por cierto, está también en perfecta consonancia con el epígrafe de Manuel Azaña que introduce la novela). No tiene desperdicio, y empieza puntualizando, de manera tan oportuna como certera, la diferencia entre memoria e historia:

La historia es un saber difícil que requiere largas investigaciones, ofrece muchas incertidumbres y da a veces amargas noticias. La memoria no se investiga, sólo se recupera, sin exigir mucha disciplina, incluso, muchas veces, con un propósito de afirmación personal o colectiva que nadie está autorizado a discutir, ya que la memoria, por definición, le pertenece al que la posee. La memoria, si no es vigilada por la razón, tiende a ser consoladora y terapéutica. Modificar los recuerdos personales para que se ajusten a los deseos del presente es una tarea legítima, aunque con frecuencia tóxica, a la que casi todos nosotros somos proclives. Cuando la memoria se convierte en un simulacro colectivo su efecto empieza a ser más alarmante. Su primacía desaloja a la historia del debate público, porque la historia es mucho menos maleable, y con frecuencia puede desmentir las buenas noticias sobre el pasado que a todos nos gusta regalarnos. ("Notas")

$\mathrm{Si}$, por sincera que sea, la memoria personal puede padecer falseamientos interesados, la memoria colectiva es siempre artificial, y casi siempre interesadamente falaz. A partir de esta consideración general, AMM pasa a criticar los usos políticos e ideológicos de la memoria de la Guerra Civil, especialmente cuando funciona como "arma arrojadiza" contra el enemigo político. Frente a ello, reivindica la necesidad de una memoria no distorsionada por el partidismo; una que no excluya el trabajo o el deber de memoria pero sí se nutra de la investigación histórica. En particular y en lo personal, exalta la memoria de los valores fundamentales de la Segunda República así como el ejemplo de los pocos hombres que los defendieron hasta el final (Manuel Azaña, Juan Negrín, Max Aub...). Estos ideales republicanos son: 
defender la instrucción pública y no la ignorancia, el respeto a la ley frente a los mangoneos de los sinvergüenzas y los abusos de los criminales, el acuerdo cívico y el pluralismo democrático por encima de los lazos de la sangre o la tribu, la soberanía y la responsabilidad personal y no la sumisión al grupo o la impunidad de los que se fortifican en él. ("Notas")

Lo que se desprende de esta contraposición es que la voluntad de recuperación de los valores de la República se corresponde con la voluntad política y militante de enmendar un Presente social y político que defrauda y que, a pesar de sus alardes memoriales pero poco memoriosos, tiende a incurrir en los errores del Pasado:

¿de dónde nace la furia verbal que uno observa ahora en España, y que lo golpea a uno como un puñetazo al conectar la radio o mirar los titulares de un periódico, la voluntad desatada y al parecer casi unánime de eliminar cada uno de los espacios de concordia en los que se han basado estos treinta años de democracia y progreso? ("Notas")

La misma preocupación de fondo se observa en otros artículos como "Estado de delirio" (enero de 2007) o "La patria gutural" (octubre de 2007), en los que AMM no vacila en establecer un paralelismo entre los delirios del Presente y del Pasado. ${ }^{9}$ Al hacerlo, da un ejemplo de working memory, tal como la presenta en un artículo posterior de 2010, "Memoria crítica": "[L]a memoria que trabaja, la memoria activa, la que compara ágilmente una experiencia inmediata con otras anteriores o con ejemplos aprendidos en los repertorios culturales, la que al poner juntos elementos en apariencia lejanos entre sí descubre conexiones y posibilidades nuevas". Esto es, la memoria como función de la inteligencia e instrumento heurístico, pero cuyo funcionamiento supone que se hayan adquirido conocimientos históricos... El artículo vuelve sobre la pedagogía de la ignorancia, otra lacra del Presente, y otra traición a los ideales republicanos. ${ }^{10}$

No hace falta ampliar el corpus para darse cuenta de que AMM forja y esgrime lo que podríamos llamar un "mito republicano", en el sentido no peyorativo de un modelo axiológico y político fundacional, apto para sanear, robustecer e incluso refundar la democracia española. Este ideal late en La noche de los tiempos: si bien presenciamos el naufragio de la utopía, esta no dejaría de estar "cargada de futuro"."

NOVELA HISTÓRICA Y MEMORIA HISTÓRICA

Aunque la crítica suela negar que La noche de los tiempos sea una novela 
histórica, lo hace por manejar un concepto excesivamente estrecho (y pobre) del género. ${ }^{12}$ Basta con ampliarlo deshaciendo unos cuantos prejuicios (Lefere 17-62) para convencerse de que se trata de un magnífico ejemplo de novela histórica (además de ser, por supuesto, toda una novela, e incluso una "gran novela de amor" - como enfatiza la cubierta posterior de Seix Barral). ${ }^{13}$ En efecto, no cabe duda de que tematiza principalmente la Historia: una época y una circunstancia históricas (en Madrid, los meses previos al estallido de la Guerra Civil, con las alteraciones múltiples y cada vez más violentas de la vida política y social), la Segunda República y sus antecedentes (históricos e intelectuales), el contexto europeo del surgimiento de las ideologías totalitarias, pero también la Historia de España - la cuestión de las constantes (Muñoz, Noche 56; 82-3; 152) -, la Historia en sí (sus manifestaciones, sus dinámicas, sus continuidades y rupturas, sus signos precursores y sus huellas). ${ }^{14}$ Sobre todo, convierte en temas esenciales las diversas maneras en que los individuos hacen la experiencia de la Historia, si acaso procurando, imposiblemente, sustraerse a ella, y descubriendo hasta qué punto su identidad es condicionada por la Historia, y se revela frágilmente histórica. ${ }^{15}$ Además, la novela tematiza la cuestión de la recuperación y de la escritura del Pasado, en particular a través del discurso metanarrativo del narrador, que explicita su ambición de imposible pero irrenunciable imaginación, al servicio de la memoria: "Quiero imaginar con la precisión de lo vivido lo que ha sucedido veinte años antes de que yo naciera y lo que dentro de no muchos años ya no recordará nadie" (575). Por fin, nuestro rodeo por los artículos de AMM contemporáneos al período de escritura de la novela deja bien claro que el trabajo de representación y de interpretación del Pasado (un Pasado muy presente aún, pero no directamente experimentado por el autor) constituye, en realidad, y como ha sido a menudo el caso en la historia de la novela histórica, un comentario indirecto pero muy comprometido sobre la coyuntura presente: por una parte, a través de una representación que ambiciona abarcarlo todo (o por lo menos no eludir nada), la crítica de una memoria selectiva y partidista de la Guerra Civil y, por otra parte, gracias a la evocación potente de figuras, valores y logros emblemáticos de la República (destaca el proyecto ilustrado de la Ciudad universitaria), la reivindicación, para el Presente y su futuro, de la herencia republicana. ${ }^{16}$

Llegamos así a un primer elemento de respuesta a la pregunta que planteábamos al principio: La noche de los tiempos constituye una aportación original al debate sobre la memoria histórica porque recoge y plasma - con toda la fuerza de la ficción - las posiciones originales del autor, previamente argumentadas en sus artículos. Con estas, conviene 
recalcarlo, nos distanciamos de los paradigmas dominantes del mero reconocimiento (de los sufrimientos de las víctimas de la contienda) y de la instrumentalización política sectaria (de izquierdas o de derechas), en pro de una utilización ética y, pretendidamente, supra-política (tal como lo han reivindicado, después de Walter Benjamin, TzvetanTodorov y unos cuantos historiadores contemporáneos). ${ }^{17}$

Sin embargo, esta respuesta no es suficiente, porque no considera el posible aporte de la novela en cuanto discurso específico; en particular, si bien esta se nutre de un pensamiento no solo previo a la escritura sino extranovelesco (aunque conviene preguntarse si la experiencia del novelista no ha contribuido a conformarlo), ¿no cabe considerar que la concepción, la estructuración y la escritura de la novela conllevan un pensamiento intratextual, pertinente para el tema que nos interesa aquí?

De hecho, lo que tal vez más llame la atención son las transformaciones que, al trasladarse al ámbito de la novela, han experimentado las profundas convicciones republicanas del articulista. Por una parte, cobran una fuerza extraordinaria gracias a una representación sugerente de la coyuntura histórica que destaca la excepcionalidad y, de alguna manera, la heroicidad de la fidelidad al ideal republicano (y a la utopía humanista que lo inspiraba), y también gracias a personajes atractivos (el mismo protagonista ficticio y Juan Negrín) que son los portavoces de dichos valores $\mathrm{y}$, sobre todo, les dan vida en dicha coyuntura. Por otra parte, la fe republicana del protagonista pasa por un proceso de crisis, que llega a ponerla en entredicho (reniega incluso de su confianza voluntariosa en el progreso), ${ }^{18}$ y no acaba superándose (la novela no termina de manera esperanzadora). ${ }^{19}$ Es más, no parece que el naufragio de la utopía, que un republicano convencido debería pensar y (re)presentar como coyuntural (abriendo la perspectiva de que, aprendidas las lecciones de la Historia, la utopía podría concretarse), sea contingente. En efecto, el fracaso sería más bien una consecuencia necesaria, inherente a los arrebatos irracionales del hombre. ${ }^{20}$ Pues bien, esta fractura entre discurso extranovelesco y discurso novelesco solo puede explicarse por el mismo cambio de discurso, es decir, por las particularidades del discurso y del pensamiento novelescos.

En efecto, AMM no escribe novelas con tesis, sino verdaderas novelas, esto es, ficciones en las que se desarrollan todas las virtualidades de un pensamiento que asume plenamente, más allá de su componente reflexivo, la triple dimensión de lo subjetivo, lo afectivo y lo irracional, con las dudas, las zozobras y aun las posibles contradicciones que esto implica. Al elegir como eje de La noche de los tiempos la trayectoria existencial e intelectual de un protagonista, $\mathrm{y}$ al construir una perspectiva narrativa que acompaña 
desde la intimidad el punto de vista de este, la imaginación del autor no puede sino explorar la crisis que provoca o intensifica necesariamente, en este republicano y socialista aburguesado, la experiencia del alocamiento de la Historia y luego del exilio. Esta exploración es tanto más inquieta y aguda en cuanto que Abel resulta muy afín al autor, ${ }^{21}$ y que su comportamiento nada heroico (como, por cierto, el de la mayoría de los escritores que aparecen en el libro) debe de corresponderse con dudas muy íntimas (¿cómo habría actuado yo en aquella circunstancia?). ${ }^{22}$ La imaginación del protagonista implica asimismo la confrontación con personajes animados por convicciones contrarias, cuyas subjetividades el novelista consigue acompañar y plasmar con la misma fuerza de persuasión, de tal manera que, por ejemplo, el reformismo razonable de Abel, en sintonía con las pautas de la democracia parlamentaria, es cuestionado a lo largo del potente diálogo con el obrero Eutimio (384-401), que defiende la apuesta revolucionaria (con más autenticidad que José Bergamín, que encarna aquí la figura del ideólogo, algo oportunista). ${ }^{23}$

De manera más fundamental aún, al pasar al ámbito de la novela, las convicciones diurnas entran en el universo consolidado y muy denso del novelista, en que los sentimientos dominantes son la extranjería, el desamparo, la melancolía, para cuya potenciación el motivo ahora central de la Guerra Civil ofrece un escenario inmejorable. El mismo amor, que en las ficciones anteriores cumplía una misión redentora, acaba convirtiéndose aquí, después de una evocación admirablemente simpatizante y comprensiva, en pasión destructora y traicionera con respecto a los ideales y compromisos del protagonista, precipitando la crisis de identidad de quien se sentía partícipe de una élite intelectual y moral. Abel contesta a su amante que lo interroga acerca de "la manera recta de actuar": "Yo no sé nada. Yo no sé si soy tan farsante como los otros. Cada uno justifica como puede su comportamiento vergonzoso. Los únicos sin culpa son los inocentes sacrificados, y uno tampoco quiere ser uno de ellos" (912). Abel no es un inocente sacrificado, pero sí una víctima, en cierta medida culpable, del cainismo extremista. No es un héroe positivo, pero tampoco el antihéroe del que suele hablar la crítica; hay algo heroico en su exigencia moral y gnoseológica, típica de muchos protagonistas anteriores, salvo que aquí no desemboca en nada, sino en cierto pesimismo antropológico e histórico, que apunta a la inevitable repetición de lo mismo. Contribuye a ello el hecho de que coexistan con el ingente esfuerzo de reconstitución histórica destellos anti-históricos muy propios del pensar literario. De manera recurrente, la realidad histórica se describe en términos carnavalescos o propiamente esperpénticos, que además retoman el imaginario muy literario (y afrancesado) de la España 
negra: de la "loca fiesta trágica", citando a Juan Ramón Jiménez (712), a "la siniestra charlotada española ... los desfiles castrenses a ritmo de paso doble, la mugre eterna de la fiesta nacional ... fiebre de carnaval y de catástrofe" (618-619). ${ }^{24}$ Por otra parte, una memoria mítica, que es como el equivalente nocturno de la working memory, tiende a reconocer en los dramas de la Guerra Civil el retorno de violencias primitivas o arcaicas, que nos devuelven a maldiciones bíblicas y a "la noche de los tiempos" $(576-7 ; 630 ; 682 ; 787)^{25}$

Así pues, el pensamiento intratextual acaba socavando al extratextual, a la par que lo potencia, contextualiza y hace más complejo. Al mismo tiempo, la vocación universalizante de la novela lleva a plantear numerosas reflexiones de carácter general relativas a la experiencia de la Historia: cómo esta afecta la percepción del tiempo y de la identidad personal y colectiva (Soubeyroux), cómo se articulan pasiones individuales y colectivas, cuáles son las diversas modalidades de comportamiento individual y colectivo en el trance de una crisis histórica... Todas son fundamentales y conforman la dimensión simbólica y ejemplar de la novela. ${ }^{26}$ Pero la más obsesiva, la más inquieta y estimulante deriva de la peculiaridad de una perspectiva narrativa que ambiciona trasladarnos al horizonte histórico de los personajes (en especial, a su Presente que desconoce el Futuro), a su inevitable y angustiosa ceguera histórica; se refiere al misterioso proceso de la Historia y se declina en varias preguntas: ¿Cuáles son, en el indescifrable Presente, los signos del Futuro?, ¿cuáles son los que podemos ver pero preferimos no ver?, ${ }^{27}$ ¿cuándo lo nuevo y anormal se convierte en habitual y normal, manifestando el cambio de época?, ¿cuándo se pasa de una situación a otra?, ¿cuál es el momento decisivo? ${ }^{28}$ Este conjunto de preguntas, que remiten a la problemática del conocimiento histórico, son sin duda las más inquietantes por ser las que más directamente interpelan al lector (de 2009, y de cualquier época posterior) y a su working memory, obligándole a cuestionar su lucidez histórica.

Podemos volver ahora a nuestra pregunta inicial: ¿en qué medida y de qué manera La noche de los tiempos constituye una aportación original a la memoria de la Guerra Civil y al debate sobre la memoria histórica? Pues, sus aportes están a la altura de lo que se puede esperar de cualquier gran novela histórica y, desde el punto de vista estructural, se dejan cifrar en tres categorías: representación, ejemplaridad y metadiscurso.

La representación no se apoya en ninguna experiencia directa del Pasado evocado, sino en la memoria personal de la memoria familiar y de las diversas memorias públicas (desde el franquismo hasta la actualidad de la escritura) y, sobre todo, en documentos de todo tipo, en los que destacan 
los textos literarios (diarios, memorias, novelas), los ensayos históricos, los artículos periodísticos de la época, fotografías... ${ }^{29} \mathrm{~A}$ partir de este material tan amplio y variado, ese genio de la narración y de la mise en intrigue (Ricoeur) que es el gran novelista ha conseguido condensar en una historia tan rica como convincente una cantidad prodigiosa de información, que nos da la ilusión de abarcar y entender, en apenas 900 páginas, la coyuntura histórica española de 1935-1936; no desde el Presente de la lectura, sino gracias a la ficción que permite abordar dicha coyuntura a través de las subjetividades contrastadas de quienes la vivían, sumidos en ese Pasado, con su polifonía de voces y de puntos de vista. ${ }^{30}$ Una representación, es decir, una propuesta de memoria tan rica, constituye de por sí una crítica radical de las memorias selectivas y partidistas de la Guerra Civil. Es cierto que AMM ha elegido como escenario Madrid (emblemática en la memoria izquierdista de la Guerra Civil, como puede ser Toledo para las derechas), y a un republicano socialista como protagonista, pero hemos visto que la evocación de la situación políticosocial de la capital en los meses previos al conflicto y en los primeros meses de este resulta del todo desmi(s)tificadora, de la misma manera que la imaginación del protagonista, que ahonda en sus zozobras, contradicciones y traiciones, hasta llega a poner en entredicho sus convicciones republicanas y progresistas.

Ahora bien, por muy puntual y aguda que sea La noche de los tiempos en su representación del Pasado, la novela no deja de acatar el antiguo principio de preceptiva moral y filosófica, y tiende hacia la ejemplaridad. Esta tendencia se manifiesta principalmente de dos maneras. En primer lugar, el planteamiento, a partir de la experiencia de la Guerra Civil, de reflexiones filosóficas y morales de carácter general en que destacan las que se refieren al enfrentamiento del individuo con la Historia y a sus interrogaciones sobre esta. En segundo lugar, la confrontación de la circunstancia histórica representada con otras análogas: por una parte, de forma explícita, hacia un Pasado que funciona como proféticamente ejemplar para ella (en la novela, la experiencia histórica de Rossman, testigo y víctima de los triunfos del nazismo y del comunismo, prefigura el destino de Abel); y por otra parte, de forma implícita (si bien lo han explicitado los comentarios peritextuales del autor así como, mutatis mutandis, el ensayo Todo lo que era sólido), hacia el Presente de la escritura y el contexto sociopolítico de una España en que campan a sus anchas los partidismos y extremismos políticos, en especial los que instrumentalizan la cuestión de la memoria histórica. En la mejor tradición de la novela histórica, La noche de los tiempos ofrece a ese Presente un espejo cóncavo donde mirarse e, inspirándose en lo mejor de la herencia republicana, 
escarmentar. Por fin, las mentiras de la memoria partidista y de sus discursos simplistas se critican también a través del escrupuloso metadiscurso del narrador que, a lo largo de la novela, explicita con lucidez las inevitables limitaciones pero también las irrenunciables ambiciones de su trabajo de recuperación del Pasado, dramatizando la tensión referencialista al tiempo que la tensión entre referencialismo e imaginación - "Importa la precisión extrema. Nada real es vago" (22) -, y contraponiendo de esta manera, a las malas y mentirosas ficciones de la ideología, las mentiras verídicas de la ficción novelesca.

\section{Université libre de Bruxelles}

\section{NOTAS}

$1 \quad$ Pongo las comillas porque es cierto que, demasiadas veces, "rather than a real give-and-take, the exchanges among disagreeing parties have largely consisted of a repetition of moves interspersed with personal insult" (Faber 14). El autor hace un balance de las diversas posiciones y polémicas, y procura identificar las condiciones que permitirían un verdadero debate.

2 Así se introduce en el Boletín Oficial del Estado: "Ley 52/2007 por la que se reconocen y amplían derechos y se establecen medidas en favor de quienes padecieron persecución o violencia durante la guerra civil y la dictadura" (s. pág.).

3 Así lo recalca A. Gómez López-Quiñones: “The invocation of non-political initial reasons and final ends ... They seem to be appealing to a common sense of human decency, to a basic dignity and decorum that, once it is taken into consideration, would eliminate political discrepancies or at least render them ancillary and derivative. This mode of argumentation also compartmentalizes ethics and politics in a hierarchical and somewhat vertical fashion" (92-93). El autor subraya que esta postura no sería posible sin la existencia relativamente reciente de un discurso sobre los derechos humanos cuyas raíces pertenecen a la tradición política liberal (94).

4 Cuando nos referimos a cada una de las tres dimensiones del Tiempo usamos la mayúscula para recalcarlas.

5 Para un análisis técnico de la narración, se puede consultar el artículo de Enrique Arroyas. Para una presentación detallada de la intriga en función de la estructuración temporal, véase Antonio Unzué.

6 Estas citas no provienen de la novela sino del prólogo a la reedición en 2011 de un libro extraordinario de Manuel Chaves Nogales (La defensa de Madrid, 1938), donde AMM evoca en términos admirativos un hombre que destaca por 
su "integridad intelectual" y su "independencia política". Si este retrato (y el complementario que encontramos en el artículo "Justicia para un hombre justo") no fuera posterior a nuestra novela, aparecería desde luego como una de sus muchas fuentes.

7 Así lo percibe probablemente cualquier lector, y de manera más clara aun cuando se conocen la biografía y los artículos de AMM. Véase la reseña que Darío Villanueva dedicó a la novela. Por otra parte, es muy llamativo al respecto el artículo abiertamente polémico de David Becerra Mayor y Julio Rodríguez Puértolas. Si bien contiene algunos elementos interesantes, está sesgado por un partidismo que lleva a la mala fe, especialmente cuando sus autores dictaminan que la novela "no tiene más objetivo que el establecimiento de una igualación entre la izquierda radical - comunismo y anarquismo - con el fascismo" (64), "su objetivo no es otro que la degradación histórica y moral del comunismo" (66), y por lo tanto es una "novela antimarxista", que muestra "cierta connivencia con el fascismo mismo" (67). Esta última afirmación es, sin duda, "una infamia" (retomando el título de la respuesta de AMM a la carta de un lector que reprochaba la supuesta equidistancia entre Franco y Azaña), pero apunta, involuntariamente, a una cualidad de la novela: el autor logra simpatizar de manera muy convincente con todos sus personajes.

8 Ángel G. Loureiro es muy severo al respecto, hablando de un "lenguaje sentimental que no está lejos del chantaje", y recalca lo siguiente: "Al buscar ante todo una simpatía emocional, las novelas del nuevo siglo sobre la guerra civil española nunca harán reflexionar sobre el pasado porque sólo aspiran a lograr la complicidad sentimental de los lectores" (32). Es sin embargo dudoso que puedan contraponerse sin más a "las novelas sobre la guerra civil del siglo anterior", vista la enorme diversidad de unas y otras: véase el último balance de Maryse Bertrand de Muñoz (2011), quien además, desde su larga experiencia de lectora de novelas de la Guerra Civil, opina que la última hornada "se revela, en su conjunto, superior a la de épocas anteriores" (222).

9 Leemos en particular en el artículo "Estado de delirio": "En España no queda nadie o casi nadie que simpatice de verdad con el fascismo o con el comunismo, y sin embargo se oye con frecuencia creciente que al adversario se le califica de facha o de rojo, con una insensatez verbal que hiela la sangre, $y$ que revela una voluntad de ruptura de la concordia civil copiada de lo peor de los años treinta".

10 El artículo de El País "Memoria crítica" es rotundo al respecto: "Una de las sorpresas más desagradables de la democracia fue que la izquierda abandonara su viejo fervor por la instrucción pública para sumarse a la derecha en la celebración de la ignorancia. Y así se ha dado la paradoja de que 
al mismo tiempo que se cumplía el sueño de la escolarización universal triunfaba una sorda conspiración para volverla inoperante".

11 AMM afirma en "Memoria crítica" que "Quizás no falta mucho tiempo para que aparezcan de nuevo visionarios que vayan predicando por los barrios populares la utopía liberadora de la instrucción pública”.

12 "Como han señalado varios críticos, ... no es estrictamente una novela de la guerra civil, pues ésta solo aparece de soslayo; y no es tampoco una novela histórica, porque no quiere contemplar desde el presente un pasado histórico ya hecho..." (Loureiro 32). Pero en el mismo artículo Loureiro escribe: "La singularidad de La noche de los tiempos ... reside en que ... plantea de frente las relaciones entre la historia y la ficción ... intenta construir, con un grado de exhaustividad tan alto como el de las mejores historias, un pasado que alguien recuerda, creando un relato a partir de documentos que también podría usar un historiador, pero que Muñoz Molina entrama de manera diferente, creando así otro tipo de verdad acerca del pasado" (33).

13 La cubierta, en su conjunto más juiciosa de lo que suele ofrecer ese tipo de paratexto orientado por consideraciones principalmente comerciales, es algo falaz cuando presenta esta "novela de amor" como "ambientada en el año previo al inicio de la guerra civil española”. Por esencial que sea, el tema amoroso está supeditado al tema histórico, constituye un contrapunto o una modulación intrahistórica de este como por cierto sugiere el final del mismo paratexto: "la confrontación entre la desvalida necesidad personal de amor y la feroz carnavalada sangrienta de los fanatismos ideológicos que arrasan en el mundo moderno".

14 Véanse por ejemplo 630; 710. Entre los muchos signos de cambio que recoge el autor en la vida cotidiana, convirtiéndolos en simbólicos del cambio histórico, está por ejemplo la utilización del espacio en el piso de Abel (con su zona de servicio), que refleja el trastorno de las jerarquías sociales. Hay que señalar, además, cómo los procesos históricos se resaltan con la repetición llamativa de estructuras lingüísticas del tipo: "antes ... ahora / después", "ya es / es ya”, "aún / ya no"...

15 En su excelente reseña que acompañó la salida del libro, Santos Sanz Villanueva resaltaba la articulación histórica de lo individual y lo colectivo: " $L a$ noche de los tiempos trata de cómo eran los españoles y su sociedad en el tiempo de la República. No pretende Antonio Muñoz Molina documentarlo, aunque disponga de admirable, sólida y extensa información, ni hacer un ensayo sociológico o político, sino imaginarlo metiéndose dentro de la piel de un ciudadano de entonces ... Esa historia privada se imbrica en el convulso entramado colectivo del momento. El autor convierte lo particular en el soporte literario de un impresionante fresco histórico coral muy amplio: abarca el testimonio regeneracionista de un país anquilosado, las pugnas 
ideológicas irreconciliables, los antagonismos de clase, el sectarismo, la ceguera cainita, los instintos primitivos...”.

16 Véanse en particular pp. 43 y siguientes. El valor simbólico de la Ciudad Universitaria era ya explotado por Chaves Nogales en La defensa de Madrid ("La guerra en la Ciudad Universitaria”): "En el interior mismo de aquellos templos erigidos al saber comenzó una lucha salvaje, feroz, cuyos protagonistas en nada habían de diferenciarse del hombre primitivo, del auténtico cavernícola" (79). Retrospectivamente, en el ensayo Todo lo que era sólido (2013), dedicado al derrumbe español que se volvía manifiesto a partir de 2010, y a los fallos políticos, sociales y culturales que habían conducido a ello, AMM proyecta este otro Presente sobre La noche de los tiempos. Lo hace desde el mismo título (que retoma una frase de la novela: "la facilidad con la que todo lo que parecía más sólido se derrumbó en Madrid en el curso de dos otros días de julio" [541]) y de manera totalmente explícita en el pasaje siguiente: "el desasosiego, la sensación de peligro y derrumbe que eran a la vez el impulso y el tema de la escritura respondían a una experiencia del todo contemporánea, pero yo no era capaz de contarlos con los materiales de mi propio tiempo... Yo escribía sobre la ceguera de quienes no saben ver lo que está ocurriendo en medio de la agitación del presente, por distracción, por irresponsabilidad, por ir cada uno a sus propios asuntos, por la decisión en el fondo asustada de no aceptar la posibilidad del desastre, por la pura inercia de creer que las cosas son mucho más sólidas de lo que en realidad son. Pero yo tampoco veía nada, absorto en mi escritura, encerrado en 2007 en mi cápsula de tiempo de 1936" (151). Con esto, AMM apunta a una forma de lucidez inconsciente, a una sensibilidad premonitoria que enriquece la dimensión histórica (y metafórica) de La noche de los tiempos, pero que no permite considerarla como "directly allegorical of the Spanish present" (Moreiras 52); especialmente en cuanto este crítico desconoce la producción periodística anterior a la novela, que, como hemos visto, ofrece los pre-textos al mismo tiempo que el referente histórico primero.

17 Véase Gómez López-Quiñones, con sus pertinentes puntualizaciones: "There ought to be an institutionally promoted approach to this crucial past because the past (a particular version of it) should work as a tool to sponsor a set of values. In other words, the memory of the Spanish Civil War needs to be put at the strategic disposal of a new democratic core of beliefs and norms ... The Spanish Civil War (a particular memorialization of it) would be withdrawn from the pugilistic-political ring and elevated to a higher meta-political sphere of foundational values that are not (or, at least, should not be) up for confrontation. What this position seems to be asking for is 1) the removal of the Spanish Civil War from the basic democratic dynamics of unavoidable 
opposition and hostility among political positions and 2) its integration into a supra-political and ultra-democratic domain that both enables and limits the democratic game of differences and clashes" (98).

18 Así, el texto recalca lo siguiente a propósito del protagonista: “Creyéndose un escéptico, él había sido más iluso que cualquiera de ellos ... el progreso era justamente lo que estaba siendo desmentido en España” (933). De manera análoga, Abel se burlaba de las "ficciones pueriles, contagio inconsciente de novelas y películas en las que el destino permite la reunión de los amantes unos segundos antes del final" (38), pero esta soberbia racionalista será desmentida por los hechos: la novela termina con el reencuentro inesperado (aunque tan esperado) de Abel y Judith, reconociendo la fuerza del destino ... y proyectando sobre el protagonista la ironía del autor.

19 En 1997, en un artículo que valoraba el componente ético de las novelas de AMM, Gonzalo Navajas escribía a propósito de los finales que el autor "oscila entre la apertura y la clausura semántica, las alternativas múltiples y la unicidad del significado" (49); dicha oscilación se observa aún, pero ahora dentro de un mismo libro.

20 Frente al optimismo regeneracionista de Juan Negrín, a quien recuerda admirado, Abel llega a explicitar su desengaño: "Nunca existió la posibilidad verdadera de eludir el desastre; el porvenir que parecía abrirse por delante de nosotros el año 31 era un espejismo tan insensato como nuestra ilusión de racionalidad" (680).

21 El enlace entre arquitectura y literatura se hace explícito al citarse "esas palabras de Juan Ramón Jiménez que parecían la síntesis de un tratado de arquitectura": "Lo neto, lo apuntado, lo sintético, lo justo" (22). Por otra parte, está el emparentamiento implícito de I. Abel con Pedro Salinas.

22 Desde este punto de vista, la novela histórica se hace también autobiográfica, en el sentido de que constituye un espacio de exploración de las virtualidades del yo. En Pasados ejemplares. Historia y narración en Antonio Muñoz Molina, el historiador Justo Serna se proponía "reconstruir la biografía fantaseada e imaginaria de Muñoz Molina" (67); el libro, de 2004, termina con Sefarad. De manera análoga, pero desde la psicocrítica de Charles Mauron, Lourdes Franco Bagnouls pretendía desentrañar el "mito personal" de AMM, destacando la metáfora obsesiva del espejo, cuya presencia y productividad se podrían poner de relieve en la presente novela.

23 Véase por ejemplo: "Pero quizás el error estaba en él, y su incapacidad para el entusiasmo era una prueba no de lucidez sino del mezquino endurecimiento de la edad, favorecido por el privilegio, y el miedo a perderlo" (769).

24 He aquí otra muestra de una visión esperpéntica: "mojigangas de niños con escopetas de madera y retrasados mentales con las cabezas muy erguidas bajo las viseras de sombreros de papel de periódico" (693). 
25 De ahí, pero de manera abusiva, la crítica de Becerra Mayor y Rodríguez Puértolas: "No hay Historia, sólo repetición de los mismos males atávicos que, desde el principio de los tiempos, han recorrido la Historia de España" (61).

26 Jacques Soubeyroux explicita en su artículo el proceso que resume en su conclusión: "Les quelque quinze mois de la vie d'Ignacio Abel ... racontent à la fois le processus de construction de l'identité du personnage et de son ascension sociale, puis, avec les débuts de la guerre civile et l'exil qu'ils entraînent, la perte de ses repères identitaires aboutissant à une totale dissolution de cette identité" (220).

27 La ceguera histórica no es fatal, sino resultado de pereza intelectual o cobardía moral: "Hubo signos pero él no los vio, o más bien eligió no verlos... Hubiera querido saber en qué momento fue inevitable el desastre" (329).

28 La cuestión del límite constituye un eje en la temática gnoseológica y se generaliza a diversos ámbitos: ético ("En qué momento se traspasa un límite y ya no hay remedio, ya no se puede borrar la vileza" [372]), fenomenológico ("En qué momento el oído empezó a acostumbrase, a distinguir" [376]), amoroso ("Un tiempo se había acabado, una especie de inocencia que ahora empezaban a preguntarse cómo había durado tanto" [526]).

29 El autor suele citar los diarios de Manuel Azaña, los relatos de Manuel Chaves Nogales, las memorias de Arturo Barea o de José Moreno Villa, las novelas de Max Aub, los estudios de Hugh Thomas o de Gabriel Jackson, la historia oral de Ronald Fraser ... Sobre la utilización de la fotografía, véase Tello García.

30 Recordemos que, en el primer volumen del monumental Temps et récit, Paul Ricoeur llama mise en intrigue la "opération de configuration" (127) mediante la cual se articulan en una unidad significativa y productora de sentidos factores anecdóticos y heterogéneos como acontecimientos, agentes y circunstancias, causas e intenciones, casualidades...

OBRAS CITADAS

ARROYAS, ENRIQUE. "La voz narrativa como compromiso con la verdad. Análisis del narrador en la novela La noche de los tiempos, de Muñoz Molina". Ogigia 12 (2012): 19-32.

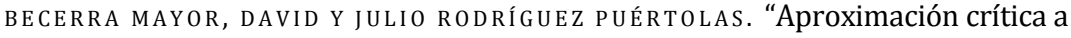
La noche de los tiempos, de Antonio Muñoz Molina”. República de las Letras: revista literaria de la Asociación Colegial de Escritores 120 (2011): 37-70.

BERTRAND DE MUÑOZ, MARYSE. "Las grandes tendencias de la novela de la guerra civil en el sigloXXI". Revista Canadiense de Estudios Hispánicos 36.1 (2011): 207225.

Cenarro, Ángela. "Francoist Nostalgia and Memories of the Spanish Civil War". International Journal of Iberian Studies 21.3 (2008): 203-217. 
Chaves nogales, manuel. La defensa de Madrid. Sevilla: Espuela de Plata, 2011. FABER, SEBASTIAAN. '“Usted, ¿qué sabe?' History, Memory and the Voice of the Witness". Revista Canadiense de Estudios Hispánicos 36.1 (2011): 9-27.

FRAn C o bagno ls, Lourdes. Los dones del espejo. La narrativa de Antonio Muñoz Molina. Madrid: Plaza y Valdés, 2001.

GómeZ Ló PeZ-Quiñones, An tonio. "A Secret Agreement: The Historical Memory

Debate and the Limits of Recognition". Hispanic Issues On Line 11 (2012): 87-116. Web.

LEFERE, ROBIN. La novela histórica: (re)definición, caracterización, tipología.

Madrid: Visor, 2013.

Loureiro, Ángel G. "En el presente incierto: La noche de los tiempos de Muñoz Molina". Ínsula 766 (2010): 30-33.

moradiellos, enrique. "Critical Historical Revision and Political Revisionism". International Journal of Iberian Studies 21.3 (2008): 219-229.

moreiras, alberto. "Time Out of Joint in Antonio Muñoz Molina's La noche de Los tiempos and Todo lo que era sólido". Romance Notes 54.1 (2014): 51-66.

MuÑ OZ M O L InA, AN T on i o. Beatus Ille. Barcelona: Seix Barral, 1986.

—. Beltenebros. Barcelona: Seix Barral, 1989.

—. El jinete polaco. Barcelona: Planeta, 1991.

—. "Estado de delirio". El País 27 enero 2007. S. pag. Web.

-. "Justicia para un hombre justo". El País 3 mayo 2010. S. pag. Web.

—. La noche de los tiempos. Barcelona: Seix Barral, 2009. S. pag. Web.

—. "La patria gutural". El País 1 octubre 2007. S. pag. Web.

—. "Memoria crítica". El País 26 marzo 2013. S. pag. Web.

—. "Notas escépticas de un republicano". El País 24 abril 2006. S. pag. Web.

—. Todo lo que era sólido. Barcelona: Seix Barral, 2013.

—. "Una infamia". El País 16 septiembre 2010. S. pag. Web.

NAVAJAS, GONZALO. "La historia como paradigma introspectivo. El modelo ético de Antonio Muñoz Molina". Cuadernos de narrativa. Ética y estética de Antonio Muñoz Molina 2 (1997): 37-53.

RICOEUR, PAUL. Temps et récit 1. L'intrigue et le récit historique. Paris: Seuil, 1983.

SANZ Villanueva, SANTos. "La noche de los tiempos". El Cultural 20 noviembre 2009. S. pag. Web.

SERnA, Jus to. Pasados ejemplares. Historia y narración en Antonio Muñoz Molina. Madrid: Biblioteca Nueva, 2004.

SOUBEYROUX, JACQUES. "Identité narrative, identité individuelle, identité collective dans La noche de los tiempos (2009) de Muñoz Molina”. Hispanística 20.29 (2011): 213-220.

TELLO GARCíA, EDGAR. "Después de la fotografía: sobre la naturaleza inconsolable en La noche de los tiempos de Antonio Muñoz Molina y Vértigo de W.G. Sebald". Moenia 16 (2010): 411-426. 
un ZuÉ, Ant on io. "Tiempo y novela en La noche de los tiempos de Muñoz Molina". Epos: Revista de Filología 26 (2010): 155-170.

Villanu Eva, DARío. "La hora del autor". Revista de libros. Segunda época 1 febrero 2010. S. pag. Web. 